\title{
El acceso web para personas con capacidades limitadas en los ayuntamientos españoles ${ }^{1}$
}

\author{
Web accessibility for people with disabilities in Spanish \\ city councils \\ 0 acesso à Internet para pessoas com capacidades limitadas nos \\ municípios espanhóis
}

INMACULADA SÁNCHEZ-LABELLA MARTÍN, Universidad de Sevilla, Sevilla, España (isanchez4@us.es] NÚRIA SIMELIO, Universitat Autònoma de Barcelona, Barcelona, España (Nuria.Simelio.Sola@uab.cat) AMPARO MORENO-SARDÀ, Universitat Autònoma de Barcelona, Barcelona, España [amparo.moreno@aub.cat]

\section{RESUMEN}

Este artículo analiza el grado de accesibilidad de las web de la administración local española para las personas con capacidades reducidas, en el contexto de la Ley de Transparencia de 2013. Se presentan 16 indicadores que permiten medir el acceso a la información por parte de usuarios con limitaciones sociodemográficas o discapacidades físicas, los que se aplicaron a las web de los 62 ayuntamientos españoles con más de 100.000 habitantes. Los resultados muestran que la administración local española no permite el empoderamiento digital de estos ciudadanos, dificultando su derecho de acceso a la información y la rendición de cuentas.

Palabras clave: administración pública; transparencia; capacidades limitadas; acceso a la información; web 2.0; gobiernos locales; comunicación pública.

\section{ABSTRACT}

This article analyzes the degree of accessibility of the websites of the Spanish local administration for people with disabilities in the context of the Transparency Law of 2013. We present 16 indicators that measure the access to information by users with sociodemographic limitations or physical disabilities, which were applied to the websites of the 62 Spanish municipalities with more than 100,000 inhabitants. The results show that the Spanish local administration does not fully allow the digital empowerment of these citizens, hindering their right of access to information and accountability.

Keywords: public administration; transparency; vulnerable citizens; access to information; Web 2.0; local government; public communication.

\section{RESUMO}

Este artigo analisa o grau de acessibilidade de pessoas com capacidades reduzidas aos sites da administração local espanhola no contexto da Lei de Transparência de 2013. Existem 16 indicadores que medem o acesso à informação por usuários com limitações sociodemográficas ou deficiências físicas. Os indicadores são aplicados aos sites dos 62 municípios espanhóis com mais de 100 mil habitantes. Os resultados mostram que a administração local espanhola não permite o empoderamento digital desses cidadãos, impedindo seu direito de acesso à informação e à prestação de contas.

Palavras-chave: administração pública; transparência; deficientes físicos; acesso à informação; web 2.0; governos locais; comunicação pública.

Forma de citar:

Sánchez-Labella Martín, I., Simelio, N. \& Moreno-Sardà, A. (2017). El acceso web para personas con capacidades limitadas en los ayuntamientos españoles. Cuadernos.info, (41), 155-173. https://doi.org/10.7764/cdi.41.1061 


\section{INTRODUCCIÓN}

Las corporaciones locales constituyen la forma más directa de relación entre la ciudadanía y la administración pública. Son la puerta de entrada de la mayoría de las peticiones de los ciudadanos de un municipio a sus representantes políticos, que a su vez tienen el deber de atenderlas, gestionarlas y procesarlas, ya sea dentro del mismo ayuntamiento o apelando a otras instituciones (Bonsón, Torres, Royos, \& Flores, 2012). En este sentido, tal y como apunta Campillo Alhama (2011, p. 1036), la ciudadanía debe estar informada y tener acceso a toda la información de las gestiones y actuaciones administrativas que puedan incidir en su situación. Se parte de la idea de que la transparencia es un principio democrático básico y que su rol en el ámbito público obliga a que las administraciones publiquen y hagan accesible la información general que pueda interesar a la ciudadanía, ya que esta entrega -mediante sus impuestos- los recursos que necesita la administración y, por lo tanto, tiene el derecho de conocer cómo utilizan estos recursos los representantes políticos (Gandía, Marrahí, \& Huguet, 2016, p. 29).

Este estudio se enmarca en un contexto en el que en España -al igual que en muchos países de la Unión Europea- ha crecido sustancialmente la desafección hacia la clase política, sumado a una falta de tradición en la transparencia gubernamental que coincide con una creciente reivindicación democrática por parte de la ciudadanía (Villoria, 2014)

Ante este escenario, en España se publicó la Ley 19/2013, de 9 de diciembre, de Transparencia, Acceso a la Información Pública y Buen Gobierno. Este documento entroniza en su preámbulo la transparencia, el acceso a la información pública y las normas de buen gobierno como "los ejes fundamentales de toda acción política"; además, puntualiza que solo cuando la acción de los responsables públicos se somete a escrutinio, cuando los ciudadanos pueden conocer cómo se toman las decisiones que les afectan, cómo se manejan los fondos públicos o bajo qué criterios actúan las instituciones, se puede hablar del inicio de un proceso en el que los poderes públicos comienzan a representar a una sociedad que es crítica, exigente y que demanda su participación.

Pese a ello, el cumplimiento de la ley por parte de las administraciones no ha sido uniforme y sigue existiendo el problema de la falta de facilidades para que los usuarios puedan acceder a esta información de forma inteligible (Beltrán Orenes \& Martínez-Pastor, 2016).
Esta ley ha tenido ya su transposición en casi todas las comunidades autónomas españolas, como por ejemplo Cataluña, que al cabo de un año aprobó su propia norma autonómica: la Llei 19/2014, del 29 de desembre, de transparencia, accés a la informació i bon govern. La comisión parlamentaria que acabó elaborándola escuchó, entre muchos otros comparecientes, a los responsables del Laboratorio de periodismo y comunicación para la ciudadanía plural de la Universidad Autónoma de Barcelona (Moreno Sardà, Molina Rodríguez Navas, Corcoy Rius, Aguilar Pérez, \& Borràs Farran, 2013), que es el equipo de investigación del que formamos parte las personas que presentamos este artículo. Durante esta etapa hemos definido los criterios, metodologías y herramientas de análisis de las web de los municipios para incentivar la participación de la ciudadanía plural en el control democrático y fomentar la buena comunicación de las instituciones, partiendo de la premisa de que las administraciones públicas son fuentes esenciales de información.

El Mapa Infoparticipa ${ }^{2}$, resultado empírico de dichas investigaciones (Moreno et al., 2013), es una plataforma online que fue desarrollada a partir de 2012 con el propósito de colaborar para subsanar la falta de una legislación española sobre transparencia. El principal objetivo de este proyecto -que se extendió en una primera fase a las comunidades autónomas de Cataluña, Canarias, Madrid, Andalucía, Aragón y Galicia, y actualmente a todas las comunidades de España con la incorporación de 52 indicadores adaptados a la Ley de Transparencia- fue evaluar la información para conseguir que las administraciones públicas mejoraran sus prácticas comunicativas y ofrecieran una información transparente, completa y comprensible, para que la ciudadanía pudiera ejercer su legítimo derecho al control y a la evaluación democrática de las instituciones. Sin embargo, era necesario considerar que esta información no solo debe ser publicada de forma accesible y transparente, sino que toda la ciudadanía plural de las sociedades en las que vivimos ha de tener acceso a ella. Por esto, el artículo que presentamos se relaciona con una nueva fase en el desarrollo de estas investigaciones previas y se propone crear una serie de nuevos indicadores que permitan analizar específicamente si los ayuntamientos españoles llevan a cabo una buena praxis en lo referido al acceso de los ciudadanos con capacidades reducidas a la rendición de cuentas y su empoderamiento como grupo social desfavorecido en cuanto a la accesibilidad a la información web. 


\section{MARCO TEÓRICO}

\section{LA CREACIÓN DE UN DISEÑO WEB PARA TODOS}

En la sociedad actual, en la que el desarrollo tecnológico es el protagonista, el acceso a la web de forma universal es una necesidad creciente para toda la ciudadanía. Por esta razón, resulta paradójico que Internet genere barreras de acceso a los contenidos para determinados colectivos de usuarios, especialmente para las personas afectadas por alguna discapacidad. Tal y como indica Fernández Aquino, "romper las barreras digitales en la web es una labor de muchos colectivos y organismos sensibilizados con su importancia entre los que juegan un papel muy importante las administraciones públicas y los organismos internacionales" (2009, p. 6).

A fines de la década de los noventa, el concepto de diseño universal introduce el debate de si es posible confeccionar un diseño web accesible para todas las personas. En este contexto, Stephanidis, Akoumianakis, Sfyrakis y Paramythis (1998) aclaran que este concepto no implica necesariamente que un único diseño deba ser adecuado para todos los usuarios, pero sí que su diseño debe intentar satisfacer las necesidades de acceso del mayor número de usuarios posible. Sin embargo, Newell y Gregor (2000) y Nielsen (2003) ponen en duda que un diseño común para todos los usuarios sea la mejor decisión para acabar con las barreras de accesibilidad, ya que resultaría más eficaz la adaptación dinámica de la interfaz al usuario según sus propias necesidades y características. En esta línea, Perlman (2000) muestra la viabilidad de estas propuestas, poniendo en marcha la implementación de una interfaz de usuario multiplataforma, multiidioma y adaptable dinámicamente a los requerimientos de los usuarios.

Con base en estas premisas, es importante considerar que la normativa vigente, tanto a nivel nacional como internacional, convierte la accesibilidad en una obligatoriedad. Por lo tanto, es un aspecto que deben tener en cuenta todas las administraciones públicas en el diseño de sus web corporativas.

\section{EL COMPROMISO CON LA ACCESIBILIDAD: EVOLUCIÓN Y APLICACIÓN DESDE LA NORMATIVA LEGAL \\ La accesibilidad como ámbito de estudio se ha con-} vertido en un tema de interés prioritario tanto en el ámbito público como en el privado. Así, Marín, Lasso de la Vega y Mier (2016) han demostrado la eficacia de las web con una buena accesibilidad y usabilidad para las pymes, Sambhanthan y Good (2013) para el comercio online en los países en vías de desarrollo y Flórez,
Ruiz, Castaño, Tabares y Duque (2014), para las web que apoyan procesos educativos.

Por otro lado, diversos autores han desarrollado investigaciones para determinar los factores que pueden mejorar la accesibilidad a las web de personas con discapacidad (Hong, Trimi, Kym, \& Hyun, 2015; Garrido, Rossi, Medina, Grigera, \& Frimenich, 2014), y para los usuarios en general (Hassan Montero \& Martín Fernández, 2004; Del Valle García, 2010).

Con el objeto de establecer normas universales, en 1994 se fundó el World Wide Web Consortium (W3C), organismo internacional independiente, en el que colaboran empresas, organismos públicos y universidades con el objetivo de discutir, consensuar, crear y promover los estándares de la web. Una de las iniciativas fundamentales de este organismo ha sido la creación de la Web Accessibility Initiate (WAI), para fomentar un alto grado de accesibilidad a la web para las personas con discapacidad. Además, desde su creación en el año 1999, el W3C ha publicado una serie de pautas ${ }^{3}$ para difundir los principios de la accesibilidad web a las empresas, gobiernos, instituciones, desarrolladores y usuarios, que han sido implementadas en la legislación de diferentes países (Bravo García, 2006)

En este contexto, la variedad de la problemática de acceso que se presenta en función de las diversas discapacidades propició que, en 2012, la Asociación Española de Normalización y Certificación (AENOR) unificara en dos documentos todos los posibles problemas detectados para discapacidades visuales, auditivas, físicas y psíquicas, en lo referente a la interfaz de usuario, tanto del hardware como del software.

Estados Unidos fue el primer país en definir y aplicar leyes al respecto, entre las que destaca la Sección 508 en su apartado web (Gobierno de Estados Unidos). Esta sección exige que cuando las agencias federales desarrollen, adquieran, mantengan o usen tecnología electrónica de la información, deben asegurarse que los empleados con discapacidad tengan el mismo acceso y uso de dichas tecnologías que los empleados sin discapacidad.

La Unión Europea ha contribuido prestando apoyo a diversos proyectos con la finalidad de alcanzar el principio de igualdad de oportunidades en la lucha contra la discriminación digital. En esta línea, la Comisión Europea puso en marcha en diciembre de 1999 la iniciativa e-Europe: una sociedad de la información para todos, con el objetivo de conseguir que toda la ciudadanía, hogares, escuelas, empresas y administraciones estén conectadas a la red, y garantizar que la sociedad 
de la información no se traduzca en exclusión social. La Comisión Europea también aprobó el trabajo del W3C-WAI, que ha servido como punto de partida para hacer una serie de recomendaciones y obligaciones a los estados miembros. Así, se impulsó la revisión de la legislación sobre la sociedad de la información y las normas de accesibilidad aprobando, entre otros aspectos, el compromiso de que todas las administraciones públicas (locales, comarcales, provinciales, autonómicas, nacionales y europeas) tuviesen sus sitios web accesibles antes de que finalizase el año 2001.

En este contexto, se regula que las administraciones públicas europeas debían supervisar sus páginas web institucionales a partir de la elaboración de un código de buenas prácticas y con la promoción de medidas de educación y formación en accesibilidad web. Finalmente, se insta a las organizaciones que reciban fondos públicos a confeccionar sus páginas web siguiendo los criterios de accesibilidad. Y es que en el Libro Verde sobre la Información del Sector Público en la Sociedad de la Información, publicado en 1998 por la Unión Europea (UE), una encuesta del Eurobarómetro confirmaba que más del 50\% de ciudadanos de los países de la Unión Europea estaban interesados en consultar y gestionar desde sus hogares y a través del ordenador todos los servicios que ofrecen las corporaciones locales.

En España, dichas exigencias se pusieron en marcha con algo de retraso. Así, la Ley 34/2002, de 11 de julio, de Servicios de la Sociedad de la Información y de Comercio Electrónico (LSSICE), plantea en sus disposiciones la accesibilidad para las personas con discapacidad y de edad avanzada a la información proporcionada por medios electrónicos.

La ley plantea que las administraciones públicas adoptarán las medidas necesarias para que la información disponible en sus respectivas páginas de Internet pueda ser accesible a personas con discapacidad y de edad avanzada de acuerdo con los criterios de accesibilidad al contenido generalmente reconocidos antes del 31 de diciembre de 2005. Dicha ley propone que todos los sitios web de las administraciones públicas (ayuntamientos, mancomunidades, provincias, comunidades autónomas, ministerios, etc.) y de aquellos organismos que estén en parte financiadas por estas (ONG, consorcios de transporte, universidades, organizaciones ciudadanas, políticas, sociales, etc.) tienen la obligación de cumplir con las exigencias propuestas. Igualmente, se promovía la adopción de normas de accesibilidad por parte de los prestadores de servicios y los fabricantes de equipos y software para facilitar el acceso de las personas con discapacidad o de edad avanzada a los contenidos digitales. Aun así, es cierto que esta ley está muy lejos de cumplirse, y aunque algunas web han hecho un esfuerzo por lograr que sus sitios cumplan por anticipado estos requisitos, los resultados en general no han sido satisfactorios. Por otro lado, aunque legalmente las empresas todavía no están obligadas a ello, el hecho de que las web de las administraciones públicas adopten la accesibilidad como un criterio de calidad puede impulsar a que el sector privado demande sitios web accesibles.

Siendo pues la digitalización la protagonista en el ámbito de la información y comunicación, tal y como exponen Muñoz Cañavate y Chaín Navarro (2005), conceptos como ciber gobierno, e-democracia o e-administración han cambiado radicalmente la antigua imagen de una administración tediosa que suponía para el ciudadano una serie de penosos y largos trámites para conseguir unos datos o información que necesitaba obtener, y a los que tenía derecho a acceder (2005, pp. 43-44). En este sentido, y con base en las políticas públicas, el entorno legal y la normativa de la e-accesibilidad, "en la última década se ha apreciado una mayor sensibilización de la sociedad hacia la no e-exclusión y más voluntad política por parte de los estados y organismos internacionales para su solución" (Fernández Aquino, 2009, p. 7).

Tal y como se ha indicado al inicio, las publicaciones en relación a este tema son numerosas. Entre los trabajos más destacados en el ámbito español, se pueden citar los realizados por Muñoz Cañavate y Chaín Navarro, quienes estudiaron el origen y evolución de los ayuntamientos españoles en la red (Muñoz Cañavate \& Chaín Navarro, 2004; Chaín Navarro, 2005; Muñoz, 2005; Chaín Navarro, Muñoz Cañavate, \& Más Bleda, 2008), así como los realizados por el Observatorio de la Infoaccesibilidad de Discapnet entre los años 2005 2008. En este caso, se analizaron los portales web de las diecisiete comunidades autónomas de España tomando en cuenta la evaluación de doce criterios de accesibilidad y la valoración de los usuarios. Los primeros resultados demostraron un panorama desolador para la sociedad digital española, pues solo la región de Murcia obtenía una valoración conjunta que superaba, y por muy poco, el 50\% de los indicadores. Posteriormente, en el año 2008, los resultados mostraron que -aunque se apreciaba una ligera mejoría de casi catorce puntos porcentuales en el resultado promedio-, los tres mejores portales del año 2005 se convirtieron en los peores de la última medición. 
Por su parte, en 2006 la Fundación CTIC $^{4}$ realizó otro estudio, que reflejaba que solo siete comunidades autónomas cumplían adecuadamente los requisitos que exige la ley para favorecer la accesibilidad a las páginas web de sus gobiernos regionales, cuatro de ellas con una calificación de muy buena (Andalucía, Cataluña, Galicia y Murcia) y el resto, buena (País Vasco, Comunidad Valenciana y Canarias). Además, Lozano, López y Ruiz (2006) propusieron crear una nueva web del Ayuntamiento de Madrid partiendo de una visión integral de la gestión de contenidos para los entornos web y con especial énfasis en las mejoras de usabilidad y accesibilidad. En 2010-2012, el Observatorio de accesibilidad de sitios web municipales, liderado por la Fundación ONCE y el Grupo Fundosa, realizó evaluaciones anuales sobre las páginas web de los ayuntamientos españoles. De dichos trabajos se concluye que el entorno web municipal se ha ido consolidado como un aspecto clave de los servicios ofrecidos por los ayuntamientos a causa de su importancia como plataforma de acceso a la información de interés público para la ciudadanía y porque permite la gestión de servicios electrónicos ofrecidos por las administraciones públicas. Sin embargo, tras los análisis realizados, se detectan malos resultados de accesibilidad en lo concerniente a los elementos multimedia, los archivos PDF, las imágenes y la posibilidad de aumentar el tamaño del texto.

También es necesario destacar otros estudios como el realizado por Salvador Oliván y Fernández Ruiz (2012), donde se presenta el mapa de procesos que se realizan en la sede electrónica del Ayuntamiento de Zaragoza, requisito para obtener el certificado Aenor-Marca N de accesibilidad TIC que garantiza el cumplimiento de las pautas de accesibilidad. Por otro lado, Atencias López (2015) analiza la relación entre la administración pública y los ciudadanos a través de las nuevas tecnologías y presenta una serie de mejoras para garantizar su eficiencia, productividad y accesibilidad de las gestiones electrónicas.

Pero no solo en España se detectan dificultades en cuanto a la accesibilidad web para la ciudadanía incluidos aquellos con deficiencias físicas. Lazar, DudleySponauble y Dawn Greenidge (2004) afirman que "dado que las herramientas y las directrices están disponibles para ayudar a construir sitios web accesibles, y dado que las políticas públicas generalmente admiten la accesibilidad web, es sorprendente que tantos sitios web sean inaccesibles" (2004, p. 284). Del mismo modo, Chiang, Cole, Gupta, Kaiser y Starren (2005) subrayan que, a pesar de los avances tecnológicos, aún persisten múltiples dificultades para el acceso de personas con discapacidad visual a la información online.

En un trabajo más actual, Bakhsh y Mehmood (2012) demuestran que "en Pakistan es muy difícil o imposible para una persona con discapacidad visual acceder a la información pública a través de la web del gobierno porque los sitios web no están desarrollados de acuerdo a los estándares de accesibilidad propuestos por la W3C" (2012, p. 347). Por ello denuncian que "la inaccesibilidad de la información para los discapacitados causa discriminación", "los sitios web gubernamentales deben hacer que estas personas estén continuamente informadas" (2012, p. 347).

Por su parte, Fernández Vásquez, Acevedo, Mariño María, Godoy y Alfonzo (2012) se centraron en medir la accesibilidad en dos web municipales de las provincias pertenecientes al noreste de Argentina. Sus resultados mostraron que, aunque se cumplen con algunas de las pautas especificadas por WAI respecto de los conceptos de accesibilidad aplicados y los mínimos criterios correctamente implementados, estas parecen ser más una coincidencia que un conocimiento de los responsables técnicos y políticos sobre este tema (2012, p. 268).

Con todo ello, es importante destacar que la mayoría de los recursos y fuentes consultadas abordan el tema de la accesibilidad centrados exclusivamente en los usuarios con discapacidad visual, sonora y motriz, sin tener en cuenta que, tal como indica Nielsen, "el concepto de discapacidad tiene que ser muy amplio cuando se trata de la web" (2000, p. 298). En este estudio somos conscientes de que se deberían tener en cuenta otros tipos de discapacidades como, por ejemplo, las relacionadas con lo cognitivo, pero "lamentablemente éstas no han supuesto tanta investigación a nivel de la interfaz como las discapacidades físicas, por lo que las directrices para dar soporte a estos usuarios no están muy bien establecidas" (Nielsen, 2000, p. 310).

Así, y para una correcta evaluación de las web, se han de tener en cuenta estudios previos que expongan o delimiten las pautas a seguir para crear páginas que permitan la accesibilidad de las personas con cualquier tipo de discapacidad y que disminuyan las deficiencias técnicas y de contenido que puedan producir una situación de infoexclusión o brecha digital. Según lo expuesto anteriormente, $\mathrm{y}$ teniendo en cuenta las normativas, hemos considerado como primer punto de referencia las pautas propuestas por la WAI. Estas ponen el acento en diferentes aspectos. En primer lugar, definen que las imágenes, animaciones, mapas de datos, gráficos y tablas deben aparecer siempre acompañadas de 
un texto descriptivo. En relación al contenido multimedia, se advierte que este debe proporcionar subtítulos y transcripciones de audio, así como una descripción de los vídeos. Finalmente, se hace alusión a los enlaces de hipertexto, que deben usar un texto que tenga sentido leído fuera de contexto (por ejemplo, evitando el pincha aquí) y a que la organización de las páginas debe usar encabezados y una estructura consistente.

Del mismo modo, Rodríguez Cifuentes (2000) defiende la utilización de enlaces de hipertexto y la descripción de los elementos no textuales. Advierte también que es necesaria la organización del contenido y la utilización de hojas de estilo en cascadas (2000, pp. 4-6). Por su parte, Arregui Noguer y Romero Rey (2011) denuncian que para que las personas con discapacidad visual puedan hacer uso del lector de pantalla, la página web deberá estar construida con base en las pautas de la WAI, de manera que se creen espacios web para un mayor número potencial de usuarios. Entre sus peticiones, acentúan la necesidad de crear textos alternativos basados en audios, enlaces y etiquetados con información significativa en sí misma y no vinculada al contexto, compartiendo con los estudios anteriores el no usar tablas para la representación de la información, así como la necesidad de añadir un texto descriptivo al elemento visual (2011, p. 36).

Por otro lado, es necesario tener en cuenta los trabajos realizados por organizaciones como la $\mathrm{ONCE}^{5}, \mathrm{CNSE}^{6}$, COCEMFE $^{7}$, FEISD $^{8}$ y Fundación AUNA (2004), que también definen los principales problemas que presentan las páginas en Internet para las diferentes personas con discapacidad. Así, según estos estudios, las principales barreras para invidentes o personas con deficiencias visuales son diseños de web inaccesibles a través del sistema de síntesis de voz o el sistema táctil, escasez de estándares a la hora de buscar información, exceso de información no deseada que comporta un consumo de tiempo excesivo y que es desalentador, falta de estructuración de la información y problemas derivados del acceso a las presentaciones cada vez más gráficas de los elementos lógicos (Fundación AUNA, 2004, p. 42). Por su parte, las personas sordas denuncian la inexistencia de una traducción del contenido mediante el lenguaje de signos (Fundación AUNA, 2004, p. 56).

\section{PREgUNTAS DE INVESTIGACIÓN}

Como hemos explicado en la introducción, esta investigación parte de la necesidad de definir nuevos indicadores que amplíen los desarrollados hasta ese momento por el Mapa Infoparticipa. Esta plataforma fue concebida en el año 2012 por el Laboratorio de periodismo y comunicación para la ciudadanía plural de la Universidad Autónoma de Barcelona (LPCCP) para publicar los resultados de evaluar la información que ofrecen los ayuntamientos en sus páginas web, con el objetivo de promover su mejora. En 2016 y 2017 se ha analizado una muestra de ayuntamientos españoles aplicando 52 indicadores adaptados a la nueva legislación española de transparencia y que están relacionados con la transparencia de la corporación y la información para la participación.

Sin embargo, estas investigaciones mostraron la necesidad de ampliar estos indicadores para tener en cuenta aspectos específicos que afectan a las personas con una situación de desigualdad en relación con sus capacidades físicas o a su situación social y económica.

Teniendo en cuenta los antecedentes expuestos en el marco teórico, nos planteamos unas preguntas de investigación fundamentales:

P.1. A pesar de la normativa existente, ¿cumplen las páginas web de los ayuntamientos españoles con las normas de accesibilidad exigidas por la ley para permitir que la ciudadanía pueda tener fácil acceso a la rendición de cuentas?

P.2. ¿Permiten las páginas web de los ayuntamientos españoles el acceso a la información para la ciudadanía que está en una situación de desigualdad a causa de sus limitaciones físicas, sociales o económicas?

\section{METODOLOGÍA}

La metodología utilizada en esta investigación parte de los estudios previos desarrollados entre 2007 y 2011 por el Laboratorio de periodismo y comunicación para la ciudadanía plural de la Universidad Autónoma de Barcelona (Moreno et al., 2013), que dieron lugar al Mapa Infoparticipa.

La metodología Infoparticipa se plantea como una auditoría cívica de la transparencia y accesibilidad de las web de las administraciones públicas y como una contribución para mejorar la información y la comunicación públicas ofreciendo soluciones. Se parte de la idea que la investigación en ciencias sociales desarrollada en una universidad pública debe proporcionar soluciones innovadoras a los nuevos problemas sociales. Atendemos a la importancia de definir criterios 
de calidad en la información y la comunicación de las administraciones públicas para que puedan comportarse como fuentes de información transparentes que fundamenten la participación ciudadana (Molina, Simelio, \& Rius, 2017).

La metodología de este artículo parte del análisis de las páginas web institucionales de los ayuntamientos a partir de 16 indicadores que derivan de las preguntas expuestas en el apartado anterior. Los indicadores están formulados de manera que las respuestas solo pueden ser positivas en el caso de que exista la información y negativas en el caso de que esta no esté publicada o que lo esté de forma incompleta o inadecuada. Tanto los indicadores como la forma en la que son evaluados permiten la transparencia y la contrastación.

Los indicadores que se han establecido para evaluar las páginas web son informaciones elementales y la forma de validarlos no ofrece dudas, ya que se ha optado por redactarlos de tal forma que la respuesta solo puede ser sí o no (existe esta herramienta). Para determinarlos, se recurrió a los estudios previos expuestos en el marco teórico (WAI, 1999; Rodríguez Cifuentes, 2000; Fundación AUNA, 2004; Nielsen, 2000; Arregui Noguera \& Romero Rey, 2011).

La evaluación de los indicadores se realizó entre los meses de julio y octubre de 2016.

\section{MUESTRA}

Para la selección de la muestra se tomaron como válidas las últimas cifras de población resultantes de la revisión del padrón municipal del 1 de enero de 2015, ofrecidas por el INE9 . Se seleccionaron todos los municipios españoles con más de 100.000 habitantes. Así, se obtuvo una muestra de 62 web de los ayuntamientos de las siguientes ciudades: Almería, Algeciras, Cádiz, Jerez de la Frontera, Granada, Huelva, Jaén, Málaga, Marbella, Dos Hermanas, Sevilla, Córdoba, Zaragoza, Gijón, Oviedo, Las Palmas de Gran Canarias, Telde, San Cristóbal de la Laguna, Santa Cruz deTenerife,Santander, Badalona, Barcelona, L'Hospitalet de Llobregat, Lleida, Mataró, Reus, Sabadell, Tarragona, Terrassa, Santa Coloma de Gramenet, Albacete, Burgos, León, Salamanca, Valladolid, Alicante, Elche, Castellón de la Plana, Valencia, Badajoz, A Coruña, Ourense, Vigo, Palma de Mallorca, Logroño, Madrid, Alcalá de Henares, Alcobendas, Alcorcón, Fuenlabrada, Getafe, Leganés, Móstoles, Parla, Torrejón de Ardoz, Murcia, Cartagena, Pamplona/Iruña, Vitoria Gasteiz, Barakaldo, Bilbao y Donostia/San Sebastián.

\section{DEFINICIÓN DE INDICADORES}

Antes de la definición de indicadores, se especificaron los perfiles de usuarios a partir de sus limitaciones de acceso teniendo en cuenta los siguientes criterios: lugar de procedencia, edad, recursos económicos, formación en las TIC y discapacidades físicas (visual, auditiva y motriz). Así, se definieron las siguientes tipologías de usuarios:

- Ciudadanos extranjeros. Incluimos en esta categoría a todos aquellos ciudadanos provenientes de otros países, de habla no hispana y con dificultades en el manejo del idioma.

- Ciudadanos no experimentados. Consideramos no experimentadas a todas aquellas personas que carezcan de una formación en tecnologías de la información y de las comunicaciones.

- Ciudadanos de edad avanzada. Serán ciudadanos de edad avanzada todos aquellos que tengan más de 65 años. Según Marí Sáez (2009) y Barrantes y Cozzubo Chaparro (2015) este perfil es el que representa el índice más bajo en el uso de Internet.

- Ciudadanos con pocos recursos económicos. Serán todas aquellas personas que cuenten con ingresos mínimos, lo cual les impide hacer uso de una conexión a la red con mayor velocidad de datos. Esta situación repercute en el tiempo de acceso y carga de las páginas web que visitan.

- Ciudadanos con dificultad visual, auditiva y motriz. En este caso, nos referimos a todos aquellos ciudadanos y ciudadanas que tengan problemas, parciales o totales, de visión, audición o motricidad.

A continuación, se enumeran y explican dichos indicadores y se añaden los perfiles prioritarios de ciudadanos sobre los que repercuten.

1. Selección del idioma. Esta opción es fundamental para que todos los ciudadanos, independientemente de su lugar de origen, puedan acceder a la información. Se valida el indicador si la página web ofrece la posibilidad de elegir diferentes idiomas.Perfiles prioritarios: ciudadanos extranjeros.

2. Mapa del sitio web. Es necesario poder visualizar la composición y organización de la página de 
un solo vistazo. Se valida el indicador si la página web ofrece un enlace titulado Mapa del sitio web o Mapa web que permita ver la composición total de la página. Perfiles prioritarios: ciudadanos no experimentados.

3. Herramienta de búsqueda directa. Se valida el indicador si la búsqueda directa está señalizada mediante el verbo Ir o mediante el ícono de la lupa. Se aconseja que se utilice la lupa para que sea más reconocible. Perfiles prioritarios: ciudadanos extranjeros o ciudadanos con dificultad visual.

4. Navegación por migas. Este elemento es fundamental para indicar al usuario el recorrido realizado. Se valida el indicador si la página web ofrece al usuario la navegación por migas. Perfiles prioritarios: ciudadanos no experimentados.

5. Volver a la página de inicio. Para validar el indicador en cada una de las páginas debe aparecer la opción Inicio, Portal, Portal web, Web Ayuntamiento, para que el usuario pueda regresar a la página de inicio. Se aconseja que esta opción vaya acompañada de un ícono para ser más reconocible. Será válida cuando volver a la página principal esté indicado exclusivamente mediante una de estas cuatro opciones o todas acompañadas del ícono. No se validará si se consigue pinchando sobre el logotipo o símbolo identificativo del lugar, ya que será difícil de alcanzar por los ciudadanos poco experimentados, o teniendo que usar la opción de inicio en la navegación por migas. Perfiles prioritarios: ciudadanos extranjeros, ciudadanos no experimentados, ciudadanos con dificultad visual o ciudadanos de edad avanzada.

6. Ubicación de los elementos. Determinados elementos deben aparecer ubicados siempre en la misma zona de la pantalla para que los ciudadanos tengan una navegación rápida y eficaz. Se valida el indicador si cada una de las páginas que conforman el sitio web presenta la misma estructura y ubicación de elementos. Perfiles prioritarios: ciudadanos con dificultad motriz, ciudadanos con dificultad visual o ciudadanos de edad avanzada.

7. Diversidad de formatos de los documentos disponibles para su descarga. El objetivo es que todos los ciudadanos puedan interactuar con ellos en caso de necesidad. Se valida el indicador si se ofrece la posibilidad de descargar documentos en diferentes formatos: Word, Excel o PDF. Perfiles prioritarios: ciudadanos con dificultad visual o ciudadanos con dificultad motriz.

8. Formularios. Puesto que son complejos de manejar para algunos ciudadanos, la página web debe permitir su descarga para que estos puedan:

> Cumplimentarlos y entregarlos de forma física en cualquier administración pública.

> Enviarlos mediante cualquier otro tipo de atención telemática complementaria.

> Enviarlos a una dirección de correo como archivo adjunto.

Se valida el indicador si la web ofrece la posibilidad de descargar los formularios o rellenarlos a través de la misma página. Perfiles prioritarios: ciudadanos con dificultad visual o ciudadanos con dificultad motriz.

9. Redundancia de canal. Los elementos compositivos de la página se encargarán de acompañar o realzar la información mediante diversos canales. Se valida el indicador si la página web presenta distintos modos de acceder a una misma información, facilitándose así su localización. Perfiles prioritarios: ciudadanos no experimentados, ciudadanos de edad avanzada o ciudadanos con discapacidad visual.

10. La composición de los menús. Se valida el indicador si se cumplen los puntos indicados a continuación:

10.1. Que el sitio web presente un menú tanto vertical como horizontal, ambos de recorrido circular. Perfiles prioritarios: ciudadanos con dificultad visual.

10.2. Tener en cuenta el número de pestañas que los componen en función del tipo de menús: horizontal (5-9 pestañas) y vertical (cuando el número de pestañas es considerable). Perfiles prioritarios: ciudadanos de edad avanzada. 
10.3. Los menús desplegables tendrán una posición fija, en caso de que existan, y deben permanecer presentes cuando se accede a ellos. Perfiles prioritarios: ciudadanos con discapacidad motriz, ciudadanos de edad avanzada, ciudadanos no experimentados o ciudadanos con dificultad visual.

10.4. Los menús deben presentar etiquetas descriptivas favoreciendo la previsibilidad del contenido que el usuario encontrará una vez que acceda a ella. Perfiles prioritarios: ciudadanos no experimentados.

11. Posición de la información. Se valida el indicador si los botones o enlaces de la página web cumplen con la Ley de Fitts.

11.1. Cumplir con la Ley de Fitts, según MacKenzie (1992): los usuarios no deben recorrer con el ratón grandes distancias para llegar de un componente a otro. Es importante que al alcanzar alguno puedan manipularlos con facilidad. Perfiles prioritarios: ciudadanos con discapacidad motriz o ciudadanos de edad avanzada.

11.2. Es fundamental controlar tanto el tamaño de los elementos que suponen acciones habituales para los usuarios como su posición, debiendo estar colocados cerca de la posición de inicio. Perfiles prioritarios: ciudadanos no experimentados o ciudadanos con discapacidad motriz.

12. Textos. Se valida el indicador si se cumplen todos los puntos descritos a continuación.

12.1. Deben aparecer expuestos de un modo ágil y ameno. Perfiles prioritarios: ciudadanos con dificultad visual.

12.2. Deberán hacer uso de elementos como el color, la negrita y la cursiva para resaltar parte de la información. Perfiles prioritarios: ciudadanos con dificultad visual.

12.3. Los enlaces activos deberán estar debidamente diferenciados del resto del texto. Perfiles prioritarios: ciudadanos no experimentados o ciudadanos con dificultad visual.

12.4. Los textos deben ofrecer la posibilidad de modificar su tamaño o ser reproducidos mediante audio. Perfiles prioritarios: ciudadanos con dificultad visual o ciudadanos con dificultad auditiva.

13. Contenido multimedia. Para validar el indicador el contenido multimedia debe aparecer acompañado de subtítulos, transcripciones o su explicación mediante lenguaje de signos siendo obligatorio que un mismo vídeo ofrezca las tres opciones indicadas. No se valida el indicador si no se dan los tres casos. Perfiles prioritarios: ciudadanos extranjeros o ciudadanos con dificultad auditiva.

14. Imágenes, tablas y gráficos. Estos elementos deben ir acompañados de un texto descriptivo, ya sea redactado o audiovisual. Se valida el indicador si los elementos visuales van acompañados de texto escrito o de un audio que permita describir la información que contiene la imagen, tabla o gráfico. Perfiles prioritarios: ciudadanos con dificultad visual o ciudadanos con pocos recursos económicos.

15. Tiempo de espera en los mensajes emergentes. Estos deben esperar siempre la aceptación del usuario antes de desaparecer. Se valida el indicador si no existe tiempo de espera. Perfiles prioritarios: ciudadanos con dificultad visual o ciudadanos con dificultad motriz.

16. Uso de Adobe Flash e incorporación de plugins. Las web deben estar debidamente construidas, de modo que no exijan al usuario esta herramienta para acceder al visionado completo del contenido de la página. No se valida este indicador si la web lo exige. Perfiles prioritarios: ciudadanos no experimentados o ciudadanos con dificultad visual.

Habiéndose expuesto los indicadores necesarios, se procede a analizar cada una de las páginas web de los municipios que conforman la muestra. El momento de localización de indicadores comienza en la página de inicio y se continúa realizando una navegación completa tanto a lo largo como a lo ancho de la página. 
Los datos recogidos se trabajaron con el programa Microsoft Excel, mediante cuyas hojas de cálculo se pudo efectuar una serie de operaciones. El análisis, de carácter discriminatorio, se basa en el sistema binario de ceros y unos para indicar si se dan o no cada uno de los indicadores en la página web analizada.

\section{RESULTADOS}

Los resultados del análisis demuestran que ninguno de los ayuntamientos que conforman la muestra cumple con el 100\% de los indicadores de accesibilidad propuestos, siendo solo cuatro municipios los que superan entre el 80\%-90\% de estos. Un 58,06\% de las web de los ayuntamientos se sitúan en la franja de 70-80\% de indicadores cumplidos, 29,03\% se encuentran entre $60-70 \%$ y $3,2 \%$ entre $50-60 \%$. Solo las páginas web de dos localidades no llegarían a 20\% de los indicadores. Veamos, a continuación, los porcentajes de indicadores cumplidos según las distintas ciudades.

Por tanto, en una primera descripción de los datos se ve que la mayoría de los ayuntamientos españoles de más de 100.000 habitantes tienen en cuenta un alto porcentaje de los indicadores planteados en el momento de diseñar y publicar contenido en las web institucionales de la corporación. Así, entre los elementos más positivos hay que destacar que todas las web cuentan con la herramienta de búsqueda directa, en $74,19 \%$ no existe tiempo de espera en los mensajes emergentes, $80,13 \%$ contienen mapa de sitio web y $98,4 \%$ cumplen con la Ley de Fitts. Del mismo modo, 98,4\% de las web presenta una misma estructura y ubicación de elementos en cada una de las páginas que conforman el sitio. Sin embargo, es necesario analizar más detenidamente los aspectos más comunes que en muchos casos no se cumplen y que serían fáciles de solucionar por los responsables técnicos y políticos de las web municipales.

En primer lugar, y en lo referente al contenido multimedia, se comprueba que en ninguna de las web analizadas el contenido audiovisual aparece acompañado de subtítulos, transcripciones o reproducción mediante lenguaje de signos. Esto provoca que los ciudadanos extranjeros o los que tienen alguna discapacidad visual o auditiva no tengan posibilidad de acceder a este tipo de contenido y, por lo tanto, no se les permite tener una información transparente que facilite su papel de control de las instituciones públicas y la rendición de cuentas en el marco de una democracia participativa. A esto se suma que en $90,3 \%$ de las web no existe la posibilidad de reproducir mediante audio el contenido textual que ofrece la página. En este contexto, es importante destacar que las web de ciudades como Alicante, Valencia, Vitoria Gasteiz, Santander y Cartagena sí reproducen mediante audio todo el contenido de la página. Para ello, aplican un software conocido como Inclusite, un servicio en la nube que incrementa la accesibilidad del sitio web para las personas con dificultades, permitiendo una navegación sin dispositivos especiales ni modificaciones en la web de origen. Por su parte, ĹHospitalet de Llobregat, aunque no hace uso de dicha herramienta, sí presenta la posibilidad de reproducir los textos mediante la opción de reproducción de voz. Estos casos de buenas prácticas pueden ser ejemplos útiles para aplicar al resto de web de las instituciones públicas.

Más allá de estas ausencias, se detectan otras deficiencias referidas al acceso a los textos. Por un lado, se ha de indicar que $88,7 \%$ de las páginas web, excepto las de Lleida, Alcalá de Henares, Leganés, Parla, Torrejón de Ardoz, Murcia y Salamanca, no permiten el aumento del tamaño del texto, creando importantes dificultades a las personas con limitaciones visuales.

Por otro lado, tan solo las web de los ayuntamientos de Gijón, Badajoz, Palma de Mallorca, León, Pamplona y todas las pertenecientes a las comunidades autónomas de Cataluña, Madrid, Valencia, País Vasco, cumplen con el indicador Selección de idioma, siendo las opciones más comunes que aparecen como alternativas catalán, valenciano, euskera, inglés, francés y español; Badalona añade el alemán, Reus el ruso y japonés y Tarragona presenta un total de 53 idiomas. De este modo, se facilita el acceso a la información a la ciudadanía que proviene de otros países de lengua no hispana.

En referencia a las imágenes, es preciso indicar que su presencia puede ralentizar la carga de la página y, por ende, el acceso a la información. En este sentido, es fundamental que estas vayan acompañadas de texto por dos motivos: si se opta por desactivar la opción cargar imágenes, se favorecerá a los usuarios que por necesidad económica no gocen de una alta velocidad de conexión a Internet, y se beneficiará a los ciudadanos con dificultad visual que usen lectores de pantalla proporcionándoles la descripción del contenido. Así, y aunque tras el análisis realizado se constata que $100 \%$ de las páginas contienen imágenes para otorgar mayor dinamismo a la lectura y complementar la información redactada, tan solo en $66,1 \%$ de los casos aparecen acompañadas de un texto alternativo que describe su contenido. Este indicador resulta primordial para el acceso a la información de todos los ciudadanos, beneficiando especialmente 


\begin{tabular}{|c|c|c|}
\hline $\begin{array}{l}\text { Porcentaje de } \\
\text { indicadores cumplidos }\end{array}$ & $\begin{array}{l}\mathrm{N}^{0} \text { ciudades que lo } \\
\text { cumplen }\end{array}$ & Ciudades \\
\hline $100 \%$ & - & - \\
\hline $90-80 \%$ & 4 & $\begin{array}{c}\text { Terrassa, Donostia/ San Sebastián, L' Hospitalet de } \\
\text { Llobregat y Parla }\end{array}$ \\
\hline $80-70 \%$ & 36 & $\begin{array}{c}\text { Gijón, Pamplona, Palma de Mallorca, A Coruña, Alcalá } \\
\text { de Henares, Barcelona, Granada, Huelva, Jaén, Leganés, } \\
\text { Madrid, Reus, Alcobendas, Alcorcón, Algeciras, Cádiz, } \\
\text { Córdoba, Dos Hermanas, Jerez de la Frontera, Las Palmas } \\
\text { de Gran Canaria, Lleida, Marbella, Sabadell, Santa Coloma } \\
\text { de Gramenet, Santa Cruz de Tenerife, Vigo, Alicante, } \\
\text { Badajoz, Cartagena, Bilbao, Murcia, Valladolid, Vitoria } \\
\text { Gasteiz, Oviedo y Santander }\end{array}$ \\
\hline $70-60 \%$ & 18 & $\begin{array}{l}\text { Fuenlabrada, Getafe, Málaga, Móstoles, Ourense, Telde, } \\
\text { Torrejón de Ardoz, Barakaldo, Burgos, Elche, León, } \\
\text { Logroño, Salamanca, Badalona, San Cristóbal de la } \\
\text { Laguna, Zaragoza, Albacete, Sevilla y Tarragona }\end{array}$ \\
\hline $60-50 \%$ & 2 & Valencia y Castellón de la Plana \\
\hline $50-40 \%$ & - & - \\
\hline $40-30 \%$ & - & - \\
\hline $30-20 \%$ & - & - \\
\hline $20-10 \%$ & 2 & Almería y Mataró \\
\hline $10-0 \%$ & - & - \\
\hline
\end{tabular}

Tabla 1. Ayuntamientos que cumplen con los indicadores establecidos

Fuente: Elaboración propia.

a aquellos con discapacidad visual y a los que cuentan con conexiones lentas a Internet.

Además, se ha de destacar que $66,1 \%$ de las web presentan deficiencias en la opción Volver a la página de inicio, ya que esta no se encuentra debidamente indicada. Este hecho impide a los usuarios poco experimentados la posibilidad de volver a la posición inicial cuando se encuentren perdidos en su navegación. En este sentido, se demuestra que 41,93\% de las web no cuentan con el indicador Navegación por migas. Esta situación provoca que los ciudadanos poco experimentados o de edad avanzada tengan dificultad a la hora de saber qué recorrido han realizado y en qué lugar de la página web se encuentran.

Por otro lado, y centrándonos en los indicadores relacionados con los menús, aunque $77,4 \%$ de las páginas cuenta con menús desplegables fijos, los cuales permiten a los ciudadanos con discapacidad motriz y de edad avanzada pinchar cómodamente sobre el enlace a la información, 64,5\% de las páginas no cuentan con un menú vertical y horizontal que permita que dicha información se complemente y quede expuesta a simple vista, facilitando a los usuarios poco experimentados su localización. En cuanto a la posibilidad de acceder rápidamente a la información a través de diferentes canales, los resultados muestran que 56,45\% de las web no cumplen con el indicador Redundancia de canal, lo cual complica la navegación a la ciudadanía poco experimentada y de edad avanzada.

Siguiendo con los menús de navegación, ninguna de las web contiene menús de tipo circular, perjudicando así a los ciudadanos invidentes. Finalmente, y en relación a la obligatoriedad de instalar Adobe Flash o plugins para el acceso al contenido web, se ha de señalar que tan solo la web del ayuntamiento de Almería (1,6\% del total de las web analizadas) exige al usuario la 


\begin{tabular}{|c|c|c|}
\hline $\begin{array}{l}\text { Indicadores incumplidos } \\
\text { [los más comunes] }\end{array}$ & $\begin{array}{l}\text { Porcentaje de } \\
\text { ciudades }\end{array}$ & Perfil de ciudadano perjudicado \\
\hline $\begin{array}{l}\text { Ausencia de subtítulos, transcripciones o } \\
\text { reproducción mediante lenguaje de signos }\end{array}$ & $100 \%$ & $\begin{array}{l}\text { Ciudadanos extranjeros } \\
\text { Ciudadano con dificultad visual } \\
\text { Ciudadano con dificultad auditiva }\end{array}$ \\
\hline Ausencia de menú de navegación circular & $100 \%$ & Ciudadanos con dificultad visual \\
\hline $\begin{array}{c}\text { No existe la posibilidad de reproducir } \\
\text { mediante audio el contenido textual que } \\
\text { ofrece la página }\end{array}$ & $90,3 \%$ & Ciudadanos con dificultad visual \\
\hline No permite ampliar el texto de la página & $88,7 \%$ & Ciudadanos con dificultad visual \\
\hline No facilitan volver a la página de inicio & $66,1 \%$ & $\begin{array}{l}\text { Ciudadanos edad avanzada } \\
\text { Ciudadanos dificultad motriz }\end{array}$ \\
\hline $\begin{array}{c}\text { No permiten una localización rápida de la } \\
\text { información a través de menús verticales y } \\
\text { horizontales }\end{array}$ & $64,5 \%$ & $\begin{array}{l}\text { Ciudadanos con dificultad de avanzada edad } \\
\text { Ciudadanos no experimentados }\end{array}$ \\
\hline Redundancia de canal & $56,45 \%$ & $\begin{array}{l}\text { Ciudadanos poco experimentados } \\
\text { Ciudadanos de edad avanzada }\end{array}$ \\
\hline Imposibilidad de elegir idioma & $46,7 \%$ & Ciudadanos extranjeros \\
\hline $\begin{array}{l}\text { Disposición y acceso a archivos/ } \\
\text { documentos }\end{array}$ & $45,16 \%$ & $\begin{array}{l}\text { Ciudadanos poco experimentados } \\
\text { Ciudadanos de edad avanzada }\end{array}$ \\
\hline Navegación por migas & $41,93 \%$ & $\begin{array}{l}\text { Ciudadanos poco experimentados } \\
\text { Ciudadanos de edad avanzada }\end{array}$ \\
\hline $\begin{array}{l}\text { No presentan imágenes acompañadas de } \\
\text { un texto alternativo }\end{array}$ & $33,9 \%$ & Ciudadanos con pocos recursos económicos \\
\hline $\begin{array}{l}\text { No presentan menús desplegables } \\
\text { permanentes }\end{array}$ & $22,6 \%$ & $\begin{array}{l}\text { Ciudadanos de edad avanzada } \\
\text { Ciudadanos no experimentados } \\
\text { Ciudadanos con dificultad motriz } \\
\text { Ciudadano con dificultad visual }\end{array}$ \\
\hline
\end{tabular}

Tabla 2. Ciudadanía afectada por la inaccesibilidad a la información web

Fuente: Elaboración propia.

incorporación de Adobe Flash para acceder a un visionado completo de la página. Por su parte, la web del ayuntamiento de Barcelona obliga la incorporación de plugins para el acceso al contenido multimedia, aspectos que dificultan el acceso a la web de la ciudadanía.

Con todo ello, y tras demostrar que la inaccesibilidad de las páginas web de los ayuntamientos españoles gira en torno al acceso a los textos (escritos o audiovisuales) y la disposición de la información, es evidente que los ciudadanos más perjudicados son, en primer lugar, aquellos con dificultad visual, auditiva y motriz, seguidos de los de edad avanzada, los extranjeros, los no experimentados y quienes cuentan con pocos recursos económicos.

\section{CONCLUSIONES}

Con base en los datos obtenidos, se ha demostrado que todavía existe un importante porcentaje de web que incumplen algunas de las pautas fijadas por la WAI (1999) y AENOR (2012), lo que dificulta el acceso a la información por parte de la ciudadanía con dificultades visuales, auditivas o motrices, algo que Arregui Noguer y Romero Rey ya denunciaban en 2011. Además, es de destacar que los colectivos recogidos en la Ley 34/2002, de 11 de julio, de Servicios de la Sociedad de la Información y de Comercio Electrónico (LSSICE), que regula las disposiciones de accesibilidad para las personas con discapacidad física y de edad avanzada, 
son los que en un mayor caso se incumplen los indicadores relativos a ellos.

Nuestro estudio demuestra que las carencias y deficiencias localizadas en estudios previos (Rodríguez Cifuentes, 2000; Fundación AUNA, 2000; Nielsen, 2000; Muñoz Cañavate \& Chaín Navarro, 2004; Chaín Navarro, 2005; Fundación ONCE \& Grupo Fundosa, 2012) y relacionadas con la inaccesibilidad a la información para personas con algún tipo de discapacidad continúan existiendo en las páginas web de las instituciones públicas municipales.

Del mismo modo, podemos corroborar lo expuesto por Perurena Cancio y Moráguez Berges (2013) en relación a que la configuración de los sistemas presta mayor atención a elementos relacionados con su rendimiento o confiabilidad, pero que, sin embargo, aspectos tan relevantes como realizar un diseño interactivo que se adapte a las características específicas de cada usuario y que muestre rápidamente la información solicitada forman parte de un segundo plano. En relación a ello, demostramos que $64,5 \%$ de las web analizadas no presentan un diseño adecuado que permita una localización rápida de información mediante menús verticales y horizontales.

Con todo ello, podemos afirmar que después de más de una década de trabajos centrados en la temática de la accesibilidad web, las instituciones públicas necesitan mejorar sus páginas web institucionales en lo referido al acceso a los elementos multimedia y al texto escrito para la ciudadanía con dificultades físicas o sociales.

A pesar de esta aparente involución, si contrastamos los resultados obtenidos con los arrojados en investigaciones anteriores, se comprueba que existen ayuntamientos españoles que muestran avances en su compromiso por mejorar las condiciones de accesibilidad de sus páginas. Así, si bien el Observatorio de la Infoaccesibilidad de Discapnet (2008) señala que las web que obtuvieron la mejor posición en 2005 perdieron calidad tres años más tarde, en nuestra investigación se demuestra que existen comunidades que, con respecto a dicho estudio, han mejorado en accesibilidad. En 2006, tanto Andalucía, Cataluña como Galicia recibían la mejor calificación según el estudio realizado por la Fundación CTIC, por lo que resulta interesante indicar que los datos nos han revelado que estas mismas comunidades autónomas son las que cumplen con un mayor porcentaje de indicadores en la investigación que presentamos.

Sin embargo, y como se ha demostrado en el apartado de resultados, existen web que continúan presentando importantes carencias que impiden que los ciudadanos puedan evaluar de forma fácil y transparente la acción de los responsables de los gobiernos locales y la rendición de cuentas. Así, sería necesario que las corporaciones municipales tuvieran en cuenta que "pese a que la información en línea presenta muchas ventajas en relación a la accesibilidad en comparación con la impresa es necesario que estos espacios estén adaptados a toda la ciudadanía independientemente del lugar de procedencia, la edad, la clase social, la formación en TIC y las limitaciones físicas" (Nielsen, 2000, p. 298).

\section{DISCUSIÓN}

Tras un análisis minucioso del marco teórico antes expuesto, hemos podido alcanzar el objetivo planteado para este trabajo. Así, presentamos una metodología novedosa a partir de la definición de 16 indicadores que permiten analizar si las páginas web de los ayuntamientos españoles llevan a cabo una buena praxis en lo referido al acceso de los ciudadanos con capacidades reducidas a la información pública. Esta relación de indicadores, donde especificamos los criterios que se aplican en la evaluación de cada uno, se concibe como un instrumento para los investigadores, pero también para los responsables políticos y técnicos de las web analizadas y para cualquier ciudadano, para que puedan contrastar los datos con los que son evaluados. Esto permite que los responsables de las web institucionales puedan mejorar su información y la accesibilidad a partir de esta herramienta, siguiendo los criterios utilizados para validar cada indicador. Por tanto, la metodología utilizada puede suponer un avance social que permita la mejora de las web en relación a su accesibilidad para las personas que están en una situación de desigualdad a causa de sus condiciones físicas, sociales o económicas.

Además, si bien los indicadores marcados se han centrado en analizar las posibilidades de acceso a la información pública expuesta en las páginas web de los ayuntamientos de los ciudadanos con capacidades reducidas, la metodología presentada también se puede aplicar al análisis de otras web de carácter institucional ya que estas comparten un patrón estructural muy similar (Pérez Montoro, 2014, p. 193).

En relación a las principales preguntas de investigación podemos afirmar que las web de los ayuntamientos españoles presentan carencias en cuanto accesibilidad, lo cual provoca que existan colectivos con dificultades físicas o sociales que tienen problemas para acceder a 
la información, siendo el perfil más perjudicado el de las personas con dificultad visual, auditiva o motriz. Esta situación conlleva la falta de empoderamiento de este colectivo en el ámbito digital.

En conclusión, este estudio demuestra que, a pesar de los estudios previos realizados tanto por instituciones y organizaciones como por académicos en los que se exponían y denunciaban las carencias que las web presentaban para los usuarios vulnerables, la administración local española no ha concedido a este grupo social de ciudadanos el empoderamiento digital en lo referido al acceso a la información web, vislumbrándose lejano el objetivo de alcanzar el principio de igualdad de oportunidades en la lucha contra la discriminación.
En el contexto de la nueva Ley de Transparencia, los ayuntamientos tienen la responsabilidad de incluir tantas funciones de accesibilidad como les sea posible, cubriendo las necesidades básicas de toda la ciudadanía. Por ello, en aras de la mejora de esta realidad, se hace necesario demandar a los ayuntamientos la modificación del diseño de sus web, siendo deseable la imposición de normativas más específicas, así como el monitoreo de su cumplimiento y el establecimiento de sanciones. Se trata, en definitiva, de cumplir con el principio de igualdad de oportunidades de esta ciudadanía que demanda su derecho de acceso a la información, la transparencia y la rendición de cuentas en el medio digital.

NOTAS

1. Este artículo forma parte de una investigación I+D+i titulada Metodologías y modelos de información para el seguimiento de la acción de los responsables de los gobiernos locales y la rendición de cuentas (CS02015-64568-R (MINECO/FEDER)], financiada por el Ministerio de Economía y Competitividad y al Fondo Europeo de Desarrollo Regional (FEDER]

\section{2. http://www.mapainfoparticipa.com/index/home/}

3. http://wWw.w3.org/WAI/References/QuickTips

4. La Fundación CTIC (Centro Tecnológico de la Información y de la Comunicación) es una institución privada, sin ánimo de lucro, de carácter social y de cooperación para el desarrollo tecnológico. http://www.fundacionctic.org

5. Organización Nacional de Ciegos de España. http://www.once.es

6. Confederación Estatal de Personas Sordas. http://www.fundacioncnse.org

7. Confederación Coordinadora Estatal de Minusválidos Físicos de España. http://www.cocemfe.es

8. Federación Española de Instituciones para el Síndrome de DoWN. http://wwW.sindromedown.net

9. http://www.ine.es/jaxiT3/Datos.htm?t=2913

\section{REFERENCIAS}

AENOR (2012). Internet para todos: un desafío global, una exigencia legal, un compromiso de todos [Internet for all: a global challenge, a legal requirement, a commitment of all]. Retrieved from https:// www.aenor.es/aenor/certificacion/resp_social/accesibilidad_tic.asp\#.WdUqcUwrxmA

Arregui Noguer, B. \& Romero Rey, E. (2011). Ayudas técnicas para personas con sordoceguera [Technical aids for people with deafblindness]. In Organización Nacional de Ciegos Españoles (Eds.), La sordoceguera. Un análisis multidisciplinar [Deafblindness. A multidisciplinary analysis]. Retrieved from http://www.once.es/otros/sordoceguera/HTML/capitulo09.htm

Atencias López, J. M. (2015). Análisis y propuesta de mejora de los servicios al ciudadano en la web del ayuntamiento de Bonrepòs I Mirabel (trabajo de fin de carrera) [Analysis and proposal of improvement of the services to the citizen in the web of the municipality of Bonrepòs I Mirabel (bachelor work)]. Universitat Politècnica de València, Spain. Retrieved from http://hdl.handle.net/10251/57262 
Bakhsh, M. \& Mehmood, A. (2012). Web accessibility for disabled: a case study of Government Websites in Pakistan. In: Institute of Electrical and Electronics Engineers (Eds)., 10th International Conference on Frontiers of Information Technology, 342-347. Retrieved from http://ieeexplore.ieee.org/abstract/ document/6424347/?reload=true

Barrantes, R. \& Cozzubo Chaparro, A. (2015). Edad para aprender, edad para enseñar: el rol del aprendizaje intergeneracional intrahogar en el uso de la Internet por parte de los adultos mayores en Latinoamérica [Age to learn, age to teach: the role of intergenerational learning in the use of the Internet by older adults in Latin America]. Lima: Departamento de Economía de la Pontificia Universidad Católica del Perú. Retrieved from http://departamento.pucp.edu.pe/economia/documento/edad-para-aprender-edadpara-ensenar-el-rol-del-aprendizaje-intergeneracional-intrahogar-en-el-uso-de-la-internet-por-partede-los-adultos-mayores-en-latinoamerica/

Beltrán Orenes, P. \& Martínez Pastor, E. (2016). Grado de cumplimiento de las Leyes de transparencia, acceso y buen gobierno, y de reutilización de los datos de contratación de la Administración central española [Degree of compliance with the Laws of Transparency, access, and good governance and of the Reuse of procurement data from the Spanish central government]. El profesional de la información, 25(4), 557-567. https://doi.org/10.3145/epi.2016.jul.05

Bonsón, E., Torres, L., Royos S., \& Flores, F. (2012). Local e-government 2.0: Social media and corporate transparency in municipalities. Government Information Quarterly, 29(12), 123-132. https://doi.org/10.1016/j.giq.2011.10.001

Bravo García, A. G. (2006). Accesibilidad web. Un problema pendiente [Web accessibility. An outstanding problem]. Revista Didáctica, Innovación y Multimedia, (4), 1-23. Retrieved from http://www.raco.cat/index.php/DIM/article/view/56108/65530

Campillo Alhama, C. (2011). Investigación en comunicación municipal: estudios y aportaciones académicas [Municipal Communication Research: Academic Studies and Contributions]. Revista de Comunicación Vivat Academia, XIV(117), 1035-1048. https://doi.org/10.15178/va.2011.117E.1035-1048

Chaín Navarro, C., Muñoz Cañavate, A., \& Más Bleda, A. (2008). La gestión de información en las sedes web de los ayuntamientos españoles [Information management in the websites of Spanish city councils]. Revista Española de Documentación Científica, 31(4), 612-638. https://doi.org/10.3989/redc.2008.4.662

Chaín Navarro, C. (2005). Propuesta de un modelo bidimensional de análisis de contenido de los sistemas webs de las administraciones locales españolas [Proposal of a two-dimensional model of content analysis of web systems of Spanish local administrations]. Revista Española de Documentación Científica, 28(3), 309-333. https://doi.org/10.3989/redc.2005.v28.i3.172

Chiang, M. F., Cole, R. G., Gupta, S., Kaiser, G. E., \& Starren, J. B. (2005). Computer and World Wide Web Accessibility by Visually Disabled Patients: Problems and Solutions. Survey of Ophthalmology, 50(4), 394-405. https://doi.org/10.1016/j.survophthal.2005.04.004

Comisión Europea (1998). Libro Verde sobre la información del sector público en la sociedad de la información [Green Paper on public sector information in the information society]. Retrieved from $\mathrm{ftp} / / / \mathrm{ftp}$.cordis.europa.eu/pub/econtent/docs/gp_es.pdf

Del Valle García, P. (2010). Contribuciones tecnológicas al diseño y evaluación de un Compute Engine como elemento de salud personal sobre los paradigmas de e-Accesibilidad y usabilidad (trabajo de fin de máster) [Technological contributions to the design and evaluation of a Compute Engine as a personal health element on e-Accessibility and usability paradigms (master's degree work)]. Universidad de Zaragoza, Spain. Retrieved from http://docplayer.es/19379031-Trabajo-fin-de-masterprograma-de-doctorado-ingenieria-biomedica-director-tfm-dr-ignacio-martinez-ruiz.html

Fernández Aquino, L. C. (2009). E-accesibilidad y usabilidad de contenidos digitales. Por una sociedad de la información y el conocimiento no excluyente (tesis doctoral) [E-accessibility and usability of digital content. For a non-exclusive information and knowledge society (doctoral thesis)]. Universitat Politècnica de València, Spain. https://doi.org/10.4995/Thesis/10251/4330 
Fernández Vázquez, A., Acevedo, J. J., Mariño María, S., Godoy, V., \& Alfonzo, P. (2012). Comunicación y accesibilidad en sitios webs municipales de la región del nordeste argentino, su evaluación mediante indicadores automáticos [Communication and accessibility on municipal websites in the northeastern region of Argentina, its evaluation through automatic indicators]. Questión. Revista especializada en periodismo y comunicación, 1(35), 258-269. Retrieved from http://perio.unlp.edu.ar/ojs/ index.php/question/article/view/1530

Flórez, J., Ruiz, K., Castaño, N., Tabares, V., \& Duque, N. (2014, June). Accesibilidad en Sitios Web que Apoyan Procesos Educativos [Accessibility in Websites that Support Educational Processes]. In Duque Méndez (Chair), IX Conferencia Latinoamericana de Objetos y Tecnologías de Aprendizaje [IX Latin American Conference on Objects and Learning Technologies]. Symposium directed by the Universidad Nacional de Colombia, sede Manizales. Manizales, Colombia. Retrieved from https://www.researchgate.net/publication/290861193_Accesibilidad_en_Sitios_Web_que_Apoyan_ Procesos_Educativos

Fundación AUNA (2004). Las personas con discapacidad frente a las tecnologías de la información y las comunicaciones en España [People with disabilities in relation to information and communication technologies in Spain]. Retrieved from http://www.cermi.es/sites/default/files/docs/colecciones/ Estudio20DiscapacidadTICFundAuna.pdf

Fundación CTIC (2006). Siete comunidades autónomas cumplen los criterios de accesibilidad en sus páginas web [Seven autonomous communities meet the accessibility criteria in their web pages]. Retrieved from http://www.elmundo.es/navegante/2006/08/28/tecnologia/1156756500.html

Fundación ONCE \& Grupo Fundosa (2011). Observatorio de la Accesibilidad Universal en los Municipios de España 2011 [Observatory of Universal Accessibility in the Municipalities of Spain 2011]. Madrid: Fragma.

Gandía, J., Marrahí, L., \& Huguet, D. (2016). Digital transparency and Web 2.0 in Spanish City Councils. Government Information Quaterly, 33(1), 28-39. Retrieved from https://doi.org/10.1016/j.giq.2015.12.004

Garrido, A., Rossi, G., Medina, N., Grigera, J., \& Frimenich, S. (2014). Improving accessibility of web interface: refactoring to the rescue. Universal Access in the Information Society, 14(4), 387-399. Retrieved from http://link.springer.com/journal/10209

Gobierno de Estados Unidos, Section 508, Accesibility Program. https://www.section508.gov/

Hassan Montero, J. \& Martín Fernández, F. J. (2004). Propuesta de adaptación de la metodología de diseño centrado en el usuario para el desarrollo de sitios web accesibles [Proposed adaptation of the user-centered design methodology for the development of accessible websites]. Revista Española de Documentación Científica, 27(3), 330-344. Retrieved from http://redc.revistas.csic.es/index.php/redc/ article/view/156/210

Hong, S., Trimi, S., Kym, D., \& Hyun, J. (2015). A Delphi Study of Factors Hindering Web Accessibility for Persons with Disabilities. Journal of Computer Information System, 55(4), 28-34. http://dx.doi.org/10.1080/08874417.2015.11645784

Lazar, J., Dudley-Sponaugle, A., \& Dawn Greenide, K. (2004). Improving web accesibility: a study of webmaster perceptions. Computer in human behavior, 20(2), 269-288. https://doi.org/10.1016/j.chb.2003.10.018

Ley 19/2013, de 9 de diciembre, de transparencia, acceso a la información pública y buen gobierno [Law 19/2013, of December 9, on transparency, access to public information and good governance]. Boletín Oficial del Estado, n. 295, December 10, 2013. https://www.boe.es/buscar/act.php?id=BOE-A-2013-12887

Ley 34/2002, de 11 de julio, de servicios de la sociedad de la información y de comercio electrónico [Law $34 / 2002$, of July 11 , on services of the information society and electronic commerce]. Boletín Oficial del Estado, n. 166, July 12, 2002. https://www.boe.es/buscar/act.php?id=BOE-A-2002-13758

Llei 19/2014, del 29 de desembre, de transparencia, accés a la informació i bon govern [Law 19/2014, of 29 December, of transparency, access to information and good governance]. Diari Oficial de la Generalitat de Catalunya, n. 6780, December 31, 2014, pp. 1-38. portaldogc.gencat.cat/utilsEADOP/ PDF/6780/1395384.pdf 
Lozano Quirce, M. M., López Barranco, C., \& Ruiz Contreras, F. (2006, May-June). El nuevo portal web del Ayuntamiento de Madrid. Mejoras en accesibilidad, usabilidad e integración del modelo de gestión de contenidos [The new web portal of the Madrid City Council. Improvements in accessibility, usability and integration of the content management model]. IX Jornadas sobre Tecnologías de la Información para la modernización de las Administraciones Públicas [IX Days on information technologies for the modernization of public administrations]. Symposium directed by Tecnimap, Sevilla. Retrieved from https://administracionelectronica.gob.es/pae_Home/pae_Estrategias/pae_lineas_ccoperacion/ pae_Tecnimap/pae_TECNIMAP_2006_-_SEVILLA.html\#.Weu6ykwrzq0

MacKenzie, I. S. (1992). Fitts' law as a research and design tool in human-computer interaction. Human Computer Interaction, 7(1), 91-139. https://doi.org/10.1207/s15327051hci0701_3

Marí Sáez, V. M. (2010). Tecnologías de la información y gobernanza digital. Los usos ciudadanos de Internet en el espacio local de Jerez de la Frontera [Information technologies and digital governance. The citizen uses of Internet in the local space of Jerez de la Frontera]. HAOL, (21), 173-187. Retrieved from http://www.historia-actual.org/Publicaciones/index.php/haol/article/viewFile/423/364

Marín Dueñas, P. P., Lasso de la Vega González, C., \& Mier Terán Franco, J. J. (2016). La eficacia de la web corporativa en las pequeñas y medianas empresas: un análisis de la usabilidad web [The effectiveness of corporate Web in small and médiumsized business: an analysis of Web Usability]. Estudios sobre el mensaje periodístico, 22(1), 431-444. Retrieved from http://revistas.ucm.es/index.php/ESMP/article/view/52604

Molina Rodríguez-Navas, P., Simelio Solà, N., \& Corcoy Rius, M. (2017). Metodologías de evaluación de la transparencia: procedimientos y problemas [Methodology for transparency evaluation: procedures and problems]. Revista Latina de Comunicación Social, (72), 818-831. https://doi.org/10.4185/RLCS-2017-1194

Moreno Sardà, A., Molina Rodríguez Navas, P., Corcoy Rius, M., Aguilar Pérez, A., \& Borràs Farran, M. (2013). Infoparticip@: periodismo para la participación ciudadana en el control democrático. Criterios, metodologías y herramientas [Infoparticip@: journalism for citizen participation in the democratic control. Criteria, methodologies and tools]. Estudios sobre el mensaje periodístico, 19(2), 783-803. https://doi.org/10.5209/rev_ESMP.2013.v19.n2.43471

Muñoz Cañavate, A. \& Chain Navarro, C. (2004). Análisis comparativo regional del desarrollo de la Administración Local española en Internet (1997-2002) [Regional comparative analysis of the development of Spanish local government on the Internet (1997-2002)]. Investigación Bibliotecológica: archivonomía, bibliotecología e información, 36(18), 96-116. Retrieved from http://rev-ib.unam.mx/ib/ index.php/ib/article/view/4039

Muñoz Cañavate, A. \& Chaín Navarro, C. (2005). La Administración local española en Internet: estudio cuantitativo de la evolución de los sistemas de información web de los Ayuntamientos (1997-2002) [The Spanish local administration on the Internet: a quantitative study of the evolution of the web information systems of the municipalities (1997-2002)]. Revista Ciencias de la Información, 35(1), 4355. Retrieved from http://redc.revistas.csic.es/index.php/redc/article/view/446

Muñoz Cañavate, A. (2005). El web en la administración local española. Conclusiones de seis años de estudio [The web in the local Spanish administration. Conclusions of six years of study]. Jornadas Españolas de Documentación, 9.371-392. Retrieved from http://bauta.usal.es/bftd/bcom. php?autor=Mu\%F1oz\%20Ca\%Flavate,\%20Antonio\&inicio $=0$

Newell, A. \& Gregor, P. (2000). User Sensitive Inclusive Design: in search of a new paradigm. In J. Scholtz \& J. Thomas (Eds.), CUU 2000 First ACM Conference on Universal Usability, pp. 39-44. New York: ACM.

Nielsen, J. (2000). Usabilidad. Diseño de sitios web [Usability. Website design]. Madrid: Pearson Educación.

Nielsen, J. (2003, April 7). Alternative Interfaces for Accessibility. Message posted to https://www. nngroup.com/

Observatorio de la Infoaccesibilidad DISCAPNET (2008). Accesibilidad en los portales Web de las Comunidades Autónomas [Accessibility in the web portals of the Autonomous Communities]. Retrieved from http://www.discapnet.es/areas-tematicas/tecnologia-inclusiva/observatorio-deaccesibilidad-tic/informes-discapnet/AccesibilidadenlosPortalesWebdelasComunidadesAutonomas Revision 2007 
Pérez Montoro, M. (2014). Políticas universitarias de difusión de la información a través de la propia web institucional [University policies on information dissemination through their institutional websites]. El profesional de la información, 23(2), 190-194. https://doi.org/10.3145/epi.2014.mar.12

Perlman, G. (2000). The FirstSearch User Interface Architecture: Universal Access for any User, in many languages, on any Platform. In Proceedings of the 2000 International Conference on Intelligent User Interfaces 2000, 1-8. New York: ACM.

Perurena Cancio, L. \& Moráguez Bergues, M. (2013). Usabilidad de los sitios webs, los métodos y las técnicas para la evaluación [Usability of Web sites, methods and evaluation techniques]. Revista Cubana de Información en Ciencias de la Salud, 24(2), 176-194. Retrieved from http://www.acimed.sld. cu/index.php/acimed/article/view/405/306

Rodríguez Cifuentes, M. T. (2000). Accesibilidad a la web de las personas con discapacidad visual [Accessibility to the web of people with visual impairment]. Universidad de Murcia: Murcia. Retrieved from http://diversidad.murciaeduca.es/tecnoneet/docs/2000/III-62000.pdf

Salvador Oliván, J. A. \& Fernández Ruiz, M. J. (2012). Mapa de procesos de un sistema de gestión de accesibilidad en un servicio web de la administración pública: El Ayuntamiento de Zaragoza [Process map of the accessibility management system in a public administration web service: Saragossa City Council]. El profesional de la información, 21(3), 312-317. Retrieved from http://www.elprofesionaldelainformacion.com/contenidos/2012/mayo/13.pdf

Stephanidis, C., Akoumianakis, D., Sfyrakis, M., \& Paramythis, A. (1998). Universal accessibility in HCI: Process-oriented design guidelines and tool requirements. In Proceedings of the 4th ERCIM Workshop on User Interfaces for All, Stockholm, Sweden, pp. 19-21. Retrieved from http://ui4all.ics. forth.gr/UI4ALL-98/stephanidisl.pdf

Sambhanthan, A. \& Good, A. (2013). Implications for Improving Accessibility to E-Commerce Websites in Developing Countries-A Study of Hotel Websites. In Cornell University Library. School of Computing, University of Portsmouth, United Kingdom. Retrieved from http://arxiv.org/abs/1302.5491

Villoria, M. (2014). La transparencia como política pública en España: algunas reflexiones [Transparency as a public policy in Spain: some reflections]. EUNOMÍA. Revista en Cultura de la Legalidad, (7), 85-103 Retrieved from https://e-revistas.uc3m.es/index.php/EUNOM/article/view/2234

WAI Quick Tips Reference Card, W3C-WAI. (1999). Retrieved from http://www.w3.org/WAI/References/ QuickTips 
SÁNCHEZ-LABELLA, I., SIMELIO, N. \& MORENO-SARDĀ, A. El acceso web para personas con capacidades limitadas...

\section{SOBRE LAS AUTORAS}

Inmaculada Sánchez-Labella Martín, profesora del Departamento de Comunicación Audiovisual y Publicidad de la Universidad de Sevilla. Doctora en Comunicación por la misma Universidad. Miembro del equipo de investigación Análisis de medios, imágenes y relatos audiovisuales. Colaboradora del Laboratorio de periodismo y comunicación para la ciudadanía plural (UAB). Líneas de investigación: calidad y narrativa audiovisual, estudios de género, alfabetización audiovisual y comunicación pública. Directora I y II jornadas Enseñar a ver, aprender a mirar: educando la mirada (US).

Núria Simelio, profesora agregada del Departamento de Periodismo y de Ciencias de la Comunicación de la Universitat Autònoma de Barcelona (UAB). Es doctora en Periodismo y Ciencias de la Comunicación (UAB) y miembro del Laboratorio de periodismo y comunicación para la ciudadanía plural. Actualmente, es coinvestigadora principal del proyecto Metodologías y modelos de información para el seguimiento de la acción de los responsables de los gobiernos locales (Mineco-Feder, 2016-2018). Sus publicaciones más recientes pueden consultarse en http://orcid.org/0000-0002-9220-5155

Amparo Moreno-Sardà, doctora en Historia, catedrática emérita y directora del Laboratorio de Periodismo y Comunicación para la Ciudadanía Plural (UAB]. Proyectos más recientes como investigadora principal: HumanismePlural.com (RecerCaixa, 2014), Comunicación y periodismo para la participación ciudadana en el seguimiento y la evaluación de la gestión de los gobiernos locales (Mineco, 2013-2015), y Metodologías y modelos de información para el seguimiento de la acción de los responsables de los gobiernos locales (Mineco-Feder, 2016-2018, coinvestigadora). 